\title{
APPLYING KNOWLEDGE MANAGEMENT TO SUPPORT A VIRTUAL ORGANIZATION OF MOULD AND DIE MAKERS
}

\author{
Celson Lima', Rolando Vargas Vallejos ${ }^{2}$, Gregório Varvakis ${ }^{3}$ \\ ${ }^{1}$ Centre Scientifique et Technique du Bâtiment (CSTB), FRANCE (celson.lima@cstb.fr) \\ 2.University of Caxias do Sul, BRAZIL (rvvallej@ucs.br) \\ ${ }^{3 .}$ Federal University of Santa Catarina,BRAZIL (grego@eps.ufsc.br)
}

\begin{abstract}
This paper describes a framework to support Knowledge Management in a Virtual Organisation operating in the mould and die sector. The approach adopted aims to apply a knowledge management life cycle during the operation of a $V E$, in order to maximise the knowledge capitalisation and dissemination within the VE environment. The knowledge relevant to the creation and operation of the VE is stored in different but strongly related layers which have to be managed properly. Access rights, knowledge and information level, privacy and security-related issues are included in the framework, taking into account that each company has the right to define who can have access to and at which level of detail the knowledge publicised by such a company.
\end{abstract}

\section{INTRODUCTION}

This work focus the combination of two very challenging research areas: Virtual Enterprises (VEs) and Knowledge Management (KM). The VE paradigm has been moved from the research domain to the business application, supported by the recent developments in the Information and Communication Technologies (ICT). KM is about managing properly the knowledge possessed by an organisation, which is an invaluable vital asset for the organisation. In the classical view, the knowledge used by an organisation must be acquired and applied to solve the problems found within its business operation. The KM solutions can be deployed regardless the fact that the organisation is one single company or is a VE.

The fundamental question to be answered by this work is the following: if $\mathrm{KM}$ solutions can help single companies, it might also be applied in a VE environment with similar results? This work describes the framework where the answers to this question are searched, considering VEs from the mould and die sector operating in the south region of Brazil.

\section{VIRTUAL ENTERPRISE AND VIRTUAL ORGANIZATION}

There is no consensus about the definitions for VE and VO. In this work, the former 
is defined as a temporary alliance of enterprises that come together to share skills or core competencies and resources in order to better respond to business opportunities, and whose cooperation is supported by computer networks whilst the latter is a network of organizations that share resources and skills to achieve its mission/goal, but not limited to an alliance of enterprises. An example of VO could be a virtual municipality, associating via a computer network (Camarinha-Matos \& Afsarmanesh, 1999). It is worth noting that according to these authors, networking and cooperation are the most relevant features of both VE, VO. Despite the fact that cooperation between enterprises is not new, the use of ICT to support agile communication has added a new characteristic to those concepts.

Several projects have produced relevant contributions in this area (e.g. PRODNET-II, VEGA, PLENT, VIVE, and X-CITTIC in Europe; NIIIP in the US; VIRTEC and Virfebras in Brazil), including design and implementation of software infrastructures supporting cooperation in a VE environment, frameworks, models, and coordination systems.

\section{KNOWLEDGE MANAGEMENT}

The concept of KM has been changing due to its application in the information systems. Such a concept is proposed in the form of a sense-making model of knowledge management for the new business environment, characterised by dynamically discontinuous changes (Malhotra, 2000). The relevant KM literature presents a long list of definitions for information, knowledge and $K M$. This work has adopted the following definitions:

- Information: data with a precise meaning in a given context (Schereiber et al., 2000).

- Knowledge: information with purpose and generative capability. Knowledge is information in action (Schereiber et al., 2000). Explicit knowledge is found in tangible sources (such as paper and electronic documents, databases, etc.). Tacit knowledge is found in the expert's minds, the intangible one (Nonaka \& Takeuchi, 1995).

- Knowledge Management: the process of collecting, organizing, classifying and disseminating information throughout an organization, in order to make it purposeful to those who need it (Albert, 1998).

In order to explain the knowledge creating organizations, Nonaka \& Takeuchi have proposed a model based on the "Spiral of Knowledge Creation" which relies upon four different ways of transforming the knowledge: socialization (tacit knowledge into tacit knowledge), externalization (tacit knowledge into explicit knowledge), combination (explicit knowledge into explicit knowledge), and internalization (explicit knowledge into tacit knowledge). These transformations are partially considered in this work.

\subsection{KM life cycle}

A KM life cycle was developed taking into account two models: the "classical" cycle (Lima \& Vallejos, 2002) and the "generic" KM model, proposed by Tarapanoff (Tarapanoff, 2001). The KM life cycle proposed here comprises the 
following phases: creation, identification, search, capture, selection, validation, updating, organisation, storage, dissemination, sharing application and creation (figure 1). It is important to emphasise that this is an endless cycle in the sense that the knowledge acquisition and dissemination is a continuous cyclical process. In the creation phase we adopt the model of "Spiral of Knowledge Creation".

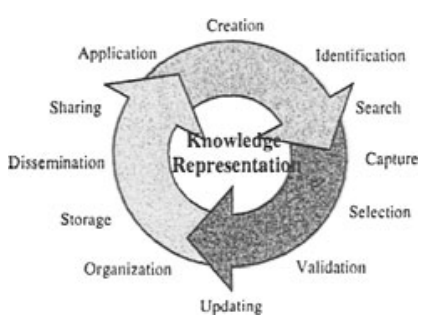

Figure 1 - The KM life cycle proposed for this work.

The generic KM model proposed by Tarapanoff was originally designed to be applied to one single organisation, and considering that to some extent a VE behaves like one single organisation, we argue that this model may be applied to VEs as well aiming at to facilitate and accelerating the creation of the organisational knowledge.

\section{THE MODEL FOUNDATIONS}

The work presented here is inspired in three projects, namely Esprit PRODNET II (www.uninova.pt/ prodnet), Virfebras and IST e-COGNOS (www.e-cognos.org).

\subsection{The PRODNET II project}

The PRODNET aimed to design and implement a software infrastructure to support VEs operation and considered that each VE member is a "node" in a network of enterprises. The PRODNET approach sees each node in a VE composed of two main modules, namely the Internal module and the PRODNET Cooperation Layer (PCL). Whilst the Internal module represents the autonomous unit, the PCL provides the link between each one of the VE members and the VE environment. The PCL comprises three major groups of functionalities, namely: (i) to support the basic inter-enterprise interactions; (ii) to support the management of contracts and the monitoring of Business Processes execution; and (iii) to support the VE global management.

In the PRODNET framework, the VE participants play two roles: Co-ordinator (VE-C) and Member (VE-M). The VE-C is responsible for the supervision of the tasks assigned to each VE-M. Inside PCL, the co-ordination-related matters were handled by a multi-layered system based on workflow concepts. Such a system exploits the fact that a VE has a common goal represented by the execution of a Distributed Business Process (DBP). The DBP is decomposed in several Business Processes (BPs) that are assigned to the VE-Ms according to their resources and competencies or following the general strategy adopted by the VE. 


\subsection{The Virfebras Virtual Organization}

Virfebras congregates nine mould and die makers located in Caxias do Sul city, south of Brazil. They share the same interest on the market and have created a cooperative environment to work together using ICT to support the interactions among themselves. The creation of Virfebras passed through several phases, namely training and education, technology set up, market strategy, benchmarking, identification of shareable resources, organizational structure, and operational issues (Galelli et al., 2001).

A VE Virfebras is created when a client order is sent. Following some previously defined and commonly accepted criteria, a Virfebras member takes over the role of $V E$ coordinator, assuming both technical and legal responsibilities for that order. For instance, one guideline used to select the VE coordinator is the following: the $V E$ coordinator will be the company that better fulfill the customer's requirements considering lead-time and price. After completion of the work (i.e., after having produced the moulds and having solved all the pending issues related to that order) the VE is dissolved. It is worth noticing that several VEs can operate at the same time and a given company that is the coordinator in one VE can be an ordinary member in others. Each company preserves its own identity and, more than that, it can decide to negotiate individually a client order, independently of the VO. A VE is instantiated only if a client order is shared by a group of companies.

Virfebras clients and members interoperate using the Virfebras information system. Each member uses a particular information infrastructure that contains a database and the appropriate software tools to manage the information about product model, mould design, production capacity, administrative and business-related issues, etc.. Each member defines, according to its own rules, the information that will be stored in the Virfebras database in order to be shared within the VO.

The Virfebras information system is accessible via an ordinary web browser or through the Information system manager. The former offers to the clients some marketing information and the current status of a given order (using access rights previously assigned to each client). The latter is used by the Virfebras members only. They can have access to the shared resources within the cluster and change the information related to their own available production capacities.

\subsection{The e-COGNOS Project}

The e-COGNOS project focus the development of a $\mathrm{KM}$ infrastructure targeting the needs from the Building and Construction (BC) sector. The project has been developing an innovative open model-based infrastructure with a set of tools that promotes effective and consistent $\mathrm{KM}$ within collaborative construction environments (Lima et al., 2002).

The e-COGNOS considers that a construction project congregates heterogeneous actors that, working in a co-operative way, need to take into account information and knowledge coming from different sources. These sources can be classified into three main groups, namely: (i) Domain layer: contains the knowledge related to the context in which a construction project is developed and includes administrative information, standards, technical rules, product databases, etc.; (ii) Corporation layer: contains the intellectual capital of a company, that exists formally in the 
company's records and informally in the company's competencies; and (iii) Project layer: contains the knowledge that each company possesses about the construction project and the knowledge generated by the inter-enterprise interactions. This knowledge includes project archives, problems and respective solutions found, etc..

This categorisation motivated the adoption of a multi-layered approach - each category previously identified corresponds to one knowledge layer - in order to support the development of the software platform called e-COGNOS Knowledge Management Infrastructure $(e-C K M I)$. The e-CKMI supports the application of the "classical $\mathrm{KM}$ cycle" in the $\mathrm{BC}$ sector. It targets the web environment and is enabled by an ontology tailored to the $\mathrm{BC}$ domain.

\section{KM IN VIRFEBRAS VO}

The Virfebras KM framework presented here relies on three pillars, namely: (i) the multi-layered approach to support KM proposed by e-COGNOS; (ii) the Virfebras information system; and (iii) the PRODNET coordination system. It aims to integrate the Virfebras information system in the PRODNET coordination system considering that in the VEs Virfebras the knowledge is stored in different layers. The e-COGNOS vision about the development of a cooperative project in the BC sector allows to recognise several characteristics found in a VE environment, such as geographically distributed partners, heterogeneity, complementarities, autonomy, ICT support, etc.. Therefore, the multi-layered approach proposed by e-COGNOS can be applied to this work as well. The vision defended here considers that in a VE, essentially, there are two layers where the knowledge is stored: the $V E$ global knowledge layer and the VE partner knowledge layer. A third layer can be added to the model - the user knowledge layer - where resides the knowledge (tacit and explicit) held by the human actors that participate directly in the VE operation.

The coordination of the KM-related tasks has to be done by a human operator. $\mathrm{He} /$ she must follow the creation of the DBP that is to be executed by a VE Virfebras as well as the assignment of the BPs to the respective VE-Ms. Furthermore, the human operator is called to participate, whenever required, in the decision-making processes related to the use of the knowledge acquired during the VE operation. The PRODNET coordination system is therefore applied to a VE that considers the two knowledge layers previously described. The VE global knowledge layer is also managed by the VE-C since it has to perform the VE global coordination. Each VE$M$ has a VE partner knowledge layer where it stores the knowledge to be shared within the VE. Finally, the human operators that participate in the VE operation represent the user knowledge layer (figure 2).

The VE Global Knowledge Layer contains the knowledge acquired during the VE live cycle, such as the DBP plan (BPs, technical aspects of the product, quality control, production processes, etc.); the status of the VE operation including conflicts/problems detected as well as the respective solutions adopted; and historical records related to the DBP execution, which may form a base of "best practices" allowing the repetition of successful cases.

The VE Partner Knowledge Layer represents what has to be shared by a VE-M with the other members of the VE. It is directly related to the BPs that are executed by a given VE-M as well as its production capacity currently offered to the VO. 
Therefore, this kind of knowledge has two distinct functions: on one hand it is intended to be used by the VE-C that is supervising the operation of a given VE and, on the other hand, it is intended to be used by future VE-Cs that are looking for potential members to take part in future VEs. An example of this kind of knowledge is the status of the BPs that are being executed, including problems detected, and the production capacity available in the VE-M.

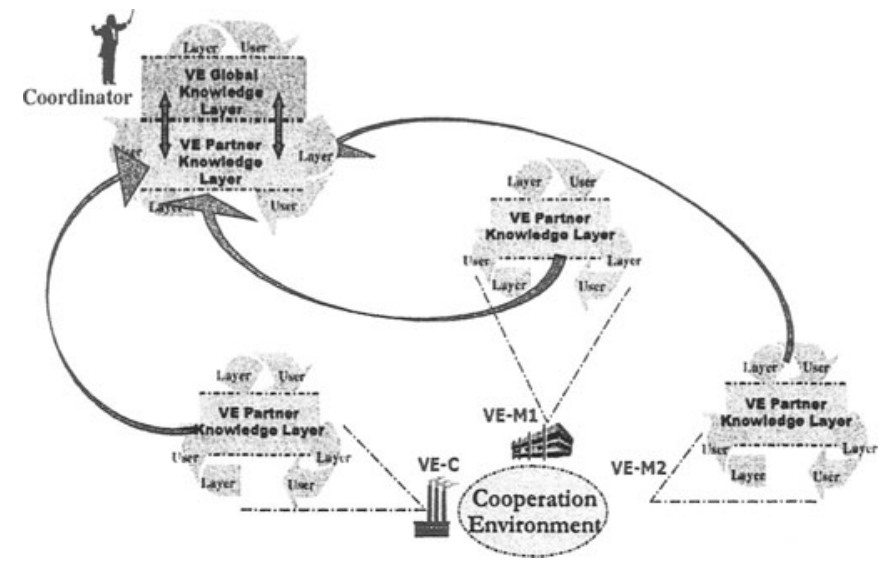

Figure 2 - General overview of the proposed framework.

A very important point to be emphasised is that each VE-M has total control on the knowledge made available on this layer. Even considering that Virfebras exists before the creation of the $\mathrm{VE}$ and that this minimises the trust-related problems that may arise, it is clear that the companies feel themselves safer and comfortable if they can define freely what is shared and how this will be done. This discussion also includes the contractual issues (from a legal point of view) that may help to define, $a$ priori, how knowledge is shared in the context of Virfebras.

\subsection{The Conceptual Framework of the Virfebras KM System}

In order to facilitate the knowledge organization in VE global knowledge and VE partner knowledge layers, we suggest, conceptually, the division of knowledge in three levels, namely: VO knowledge level, VE-M knowledge level and product knowledge level (figure 3).

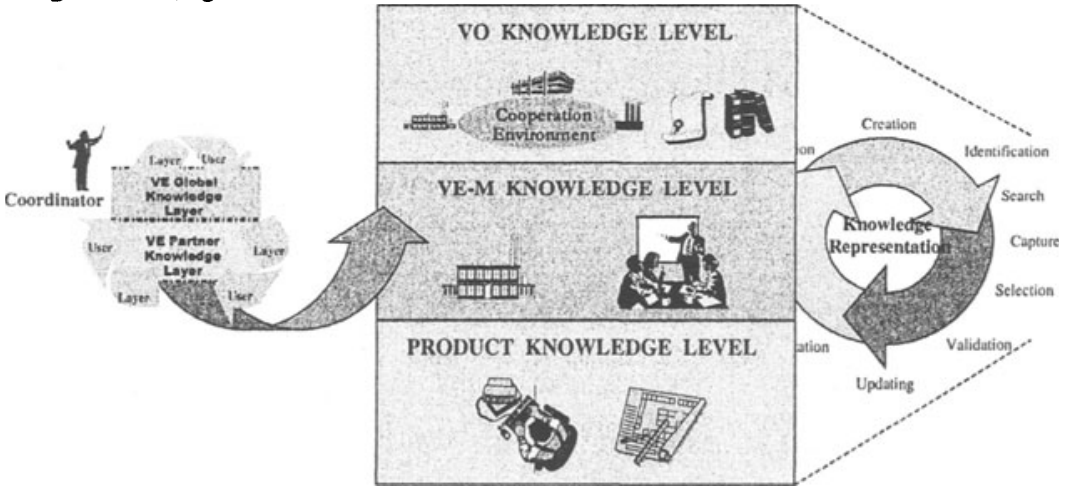

Figure 3 - Conceptual Architecture of the Virfebras VO KM Model. 
The VO knowledge level can hold an ontology, VO ethics rules, legal documentation, VO standards and procedures, historical of VEs knowledge, and DBPs (results, problems, solutions, evaluations, etc.). The VE-M knowledge level can store knowledge and information of each VE-M, historical of BPs, historical of products (projects, manufacturing processes, quality control, etc.), knowledge to be shared in EV (products, technology, etc.), and eventually some private knowledge. Finally, the Product knowledge level can hold knowledge of products being developed, and knowledge of projects, manufacturing processes being developed (private or to be shared).

If $\mathrm{KM}$ brings significant benefits for an isolated organization, it is believed that for VEs the benefits will be bigger. We believe that KM applied to VEs will accelerate the process of knowledge creation among the VE members. We also believe that KM will facilitate the application of the knowledge reuse in future works, optimizing the VE life cycle and promoting an evolution of the involved enterprises.

\subsection{Application of the Prototype}

In order to implement the prototype in the Virfebras scenario (mould and die area), three sectors were selected, namely: Project, Production Planning and Control and CAM Programming. The experts from these sectors acquired their knowledge during several years of practice and most of the time, this knowledge is tacit. It is not easy to find documents that show the explicit knowledge describing both procedures and solutions adopted/found in the previous experiences.

Each mould or die to be manufactured is usually considered as a new product. It has many sub-systems and each sub-system is formed by several components. Some of them are bought, some are manufactured by other companies and others are manufactured in house As the complexity of the moulds and dies increases, the complexity of the project, manufacturing and control of these components increases as well.

From an academic point of view, it is noticed that a mould or die would be possible to be standardised, with many similar sub-systems. For this reason it is possible to create a pattern for some procedures. Some studies show that approximately $60 \%$ to $80 \%$ of the mould or die components can follow a pattern. In order to systematize those procedures it is necessary to deeply study each one of these three sectors. Due the lack of time, the CAM programming sector was selected as the scenario to implement the prototype developed in this work. The core idea is to share the knowledge and the best practices obtained by the CAM programmers of Virfebras, considering raw-material, cutting tools, clamping devices, and mainly cutting conditions and machining strategies.

\section{CONCLUSIONS AND FUTURE WORK}

This paper described the development of a model for KM application in a VO for mould and die makers. The scenario to be used to deploy the model prototype is the Virfebras, a Brazilian VO of nine mould and die makers. Even considering that the framework presented here is in its very preliminary stage, we believe that it is 
possible to apply a KM-oriented approach in VE/VO environments in order to maximise the capitalization of the knowledge that is created or already exist in such environments. These benefits are expected to be more relevant than the ones achieved by a single organization due to the fact that $\mathrm{KM}$ mechanisms can speed up the process integration within VE/VO environments. It is argued that $\mathrm{KM}$ will facilitate the application of the knowledge reuse in future works, optimizing the VE life cycle and promoting an evolution of the involved enterprises.

Three research projects contributed to build the framework presented here, namely e-COGNOS, Virfebras, and PRODNET. Such a framework integrates the Virfebras information system into the PRODNET coordination system considering that in a VEs Virfebras knowledge is stored in different layers. In order to handle this requirement, the multi-layered approach proposed by e-COGNOS was included in the framework. This work also includes to build am ontology to the mould and die sector, to support knowledge sharing among different agents.

This work is part of a $\mathrm{PhD}$ thesis that has started the design of the prototype to be implemented and deployed within Virfebras environment in order to validate the framework shown here. This represents the future work to be done.

\section{Acknowledgements}

The authors would like to thank the people involved in the research projects used here as source of inspiration, namely e-COGNOS, PRODNET II, and Virfebras.

\section{REFERENCES}

1. Albert, S. "Knowledge Management: living up to the hype?". Midrange Systems, 1998.

2. Camarinha-Matos L. M., Afsarmanesh H. The virtual enterprise concept. In L. M. Camarinha-Matos, H. Afsarmanesh (Eds.), Infrastructures for Virtual Enterprises - Networking Industrial Enterprises, Kluwer Academic Publishers, 1999, pp. 3-14.

3. Galelli, A., Costa, C. A., Vallejos, R. V., Graciolli, O. D., Luciano, M. A. "A Virtual Organisation for the Mold and Die Industry in Brazil". In: $5^{\mathrm{TH}}$ World Multiconference on Systemics, Cybernetics and Informatics/ISAS - SCI 2001. Orlando, FL: International Institute of Informatics and Systemics, 2001. v. III, p. 303-308.

4.Lima, C., Wetherill, M., Zarli, A., Bourdeau, M., Rezgui, Y. "The e-CKMI: the e-COGNOS approach to support Knowledge Management in the Building and Construction Industry". In: ECPPM 2002 - eWork and eBusiness in AEC, Portoroz, Slovenia, September 2002.

5.Lima, C., Vallejos, R. V. "Towards a knowledge management infrastructure to support virtual enterprises". In: The European Conference on Information and Communication Technology Advances and Innovation in the Knowledge Society (eSM@RT 2002). Salford, 2002.

6. Lima, C., Tamer El Diraby, Bruno Fies, Alain Zarli, Elaine Ferneley, "The e-COGNOS project: current status and future directions of an ontology-enabled IT solution infrastructure supporting Knowledge Management in Construction". ASCE2003, Honolulu, Hawaii, March 2003.

7. Malhotra, Y., "Knowledge Management and Virtual Organizations". USA-UK, Idea Group Publishing, 2000.

8. Nonaka, I., Takeuchi, H. "The Knowledge-creating Company". Oxford UK, Oxford University Press, 1995.

9. Schreiber, A., Akkermans, H., Anjewierden A., Hoog, R., Shadbolt, N., Velde, W., Wielinga, B. "Knowledge Engineering and management: the Common KADS methodology". Massachusetts Institute of Technology, 2000.

10. Tarapanoff, K. "Inteligência Organizacional e Competitiva". Editora Universidade de Brasília, 2001. 